\title{
The Lexical Density of Erlangga's “English On Sky” Analysis
}

\author{
Gagang Ramadhan, Asih Santihastuti, Eka Wahjuningsih \\ Language and Arts Education Program, The Faculty of Teacher Training and Education \\ University of Jember \\ Jln. Kalimantan 37, Jember 68121 \\ E-mail: gagang_ramadhan@yahoo.co.id
}

\begin{abstract}
The aims of this research were to know whether the reading texts found in "English On Sky" textbook for $8^{\text {th }}$ Grade of Junior High School were appropriate and meet the content of the curriculum or not by analyzing the lexical density of its texts and identifying the type of reading text which should be given based on the KTSP curriculum. The research design used was descriptive qualitative research. The instrument of this research was document which was get from collecting the reading texts found in the textbook. The data in this study was analyzed quantitatively in the form of description and used descriptive statistics for describing the features of data. The result of this result was there was no reading text in the textbook that was categorized as high lexical density. The readi ng texts were categorized as low and moderate lexical density as there were 12 reading texts were categorized as low lexical density and 12 reading texts were categorized as moderate lexical density. 12 reading text that categorized as low lexical density had $40 \%-50 \%$ lexical density percentage. On the contrary 12 reading texts that categorized as moderate lexical density had 50\% - 60\% lexical density percentage. The highest percentage of the lexical density reading text found in the textbook was $57.72 \%$ entitled "Camping". Meanwhile, the lowest percentage of the lexical density reading text was $41.61 \%$ entitled "None of your business!". Based on the analysis, the genre found in this textbook were descriptive, recount, and narrative. In conclusion, this textbook were easy enough to understand for student and met the content of school-based curriculum.
\end{abstract}

Keywords: Descriptive Qualitative Research, Discourse Analysis, Lexical Density, Reading Text

\section{Introduction}

Reading is one of the language skills in English that students need to acquire. They need to master reading skill because by reading students can obtain information they need, understand important messages and consequently improve their knowledge. In order to make the students comprehend those texts, the English teacher has to choose suitable and appropriate materials for their student. According to Richards (2012:1), textbook is a key component in most language programs [3]. In some situations they serve as the basis for much of the language input that the learners receive and the language practice that occurs in the classroom. It means that textbook plays an important role in helping the students learning and mastering all of the language components. The composition of each language skills and its practices should be balanced to help develop student's ability during the teaching and learning process. In other words, textbook will help teacher in conducting teaching and learning process and develop student's ability in learning language. Therefore, a teacher has to be able to select and analyze the contents of textbook before they use it for teaching and learning process. In addition, a good textbook should not be too hard to be understood by student. Otherwise, it will not fulfill its purpose in delivering the materials. Textbooks with lower density are more easily to be understood compared with textbooks that the sentences are long and lexically densed. According to Nunan (1993:11), lexical density refers to the number of lexical or content word per clause [2]. Lexical density measures the proportion of content words in a sentence or text. In addition, lexical density is a term used in discourse (or text) analysis. It is used to measure the ratio of content words to grammatical words in any given text (spoken or written). As quoted by Sholichatun (2011:15) from Nunan (1993), "lexical density refers to the number of lexical content of function word per clause [4]. It measures the proportion of content words in a sentence or text. In addition, lexical density is a term used in discourse (or text) analysis. It is used to measure the ratio of content words to grammatical words in any given text (spoken or written)." It means that the lexical density measures the density of information in any passage of text, according to how tightly the lexical items (content word) have been packed into the grammatical structure. This is the measurement of how much information is provided in a particular piece of writing. Lexical words are perhaps more commonly known as content words or information words. Moreover, Sholichatun (2011:25) states that a high lexical density is around 60$70 \%$, quite lexical density measures is around $50-60 \%$, and a lower lexical density is around $40-50 \%$ [4]. According to Halliday (1985:63), lexical density is the number of lexical items which is the proportion of the number of running words [3]. He refers to use lexical items than lexical word because they may consist of more than one word, for example stand up, take over, call off, and other phrasal verbs all function as single lexical items. Based on the above explanation, lexical density is the number of content words or lexical items as a percentage of the total number of words. Content words or lexical items as opposed to function words are words that carry high information load such as; nouns, verbs, adjectives, and adverbs. If the text has more grammatical items than the lexical items, the text is categorized as the lower lexical density and this text is easy 
to understand. On the contrary, if the text has more lexical items than the grammatical ones, the text is categorized as the high lexical density and is difficult to understand but it contains a lot of information. Therefore, teachers need to be able to analyze the lexical density of the textbook to provide a suitable book which has the right level for the students.

\section{Research Method}

The design of this study was descriptive qualitative research. The instrument of this research was document which was get from collecting the reading texts found in the textbook. The data in this study was analyzed quantitatively in the form of description and used descriptive statistics for describing the features of data. This study analyzed the words to find the lexical items and grammatical words in all reading texts found in the book. Then, the result of the analysis was analyzed quantitatively by using the following formula:

\section{Lexical density $=\frac{\text { The number of lexical items }}{\text { Total words }} \times 100$}

Based on the formula aboved, the researcher categorized the text belongs to low, moderate, or high lexical density

\section{Research Result and Discussion}

Based on the result of the analysis the reading text in "English on Sky Textbook" for grade $8^{\text {th }}$ of junior high school published by Erlangga, the researcher found that there was no reading text in the textbook that is categorized as high lexical density. The reading texts were categorized as low and moderate lexical density as there were 12 reading texts were categorized as low lexical density and 12 reading texts were categorized as moderate lexical density.

The highest percentage of the lexical density found in the textbook was $57.72 \%$. It was "Camping" which was categorized as descriptive text. It had 71 lexical items, 52 grammatical function words and the total number of words was 123 . On the other hand, the lowest percentage of the lexical density was $41.61 \%$. The text entitled "None of your business!" that was categorized as recount text. It had 62 lexical items, 87 grammatical function words, and the total numbers of words were 149 .

Based on the analysis, the researcher found that the genre taught to the eighth year of Junior High School students based on School-Based Curriculum were descriptive, recount, and narrative. There were 7 descriptive texts. In which are 3 texts were categorized as moderate lexical density and 4 texts were categorized as low lexical density. Then, there were 12 recount texts in the textbook. There were texts are categorized as moderate lexical density and 7 texts were categorized as low lexical density. And the last, there were 5 narrative texts. 4 texts were categorized as moderate lexical density and 1 text was categorized as low lexical density.

The researcher found that there was no reading text in the "English On Sky" textbook for $8^{\text {th }}$ Grade that is categorized as high lexical density. The reading texts were categorized as low and moderate lexical density as there were 12 reading texts were categorized as low lexical density and 12 reading texts were categorized as moderate lexical density. Those 12 reading texts were considered to have low lexical density because as quoted from Ginting (2012:6) [1], "if the text has more grammatical items than the lexical items, the text is categorized to the lower lexical density". Those 12 reading texts found in the textbook had $40 \%-50 \%$ for their lexical density. They contained more grammatical function words than lexical items words in each text. The grammatical items that mostly came out are preposition, pronoun and determiner. If the texts contained more grammatical function words than the lexical items, it made the text easy to understand because it had less information.

Further, 12 reading texts were categorized as moderate lexical density because their lexical density was $50 \%$ to $60 \%$. They contained more lexical items than grammatical function words in each text. The lexical items that mostly came out were noun and verb. If the text had more lexical items than the grammatical function words, it could be difficult to understand by the students because the number of lexical items was higher than the grammatical function words which made the text carried more information. As quoted from Ginting (2012:6) [1], "the higher the lexical density of a text is, the more information there is and the more difficult it is to understand by readers. If the text has more grammatical items than the lexical items, the text is categorized to the lower lexical density. On the contrary, if the text had more lexical items than the grammatical items, the text was categorized to the high lexical density".

The highest percentage of the lexical density found in the textbook was $57.72 \%$. It was "Camping" which was categorized as descriptive text. It had 71 lexical items, 52 grammatical function words and the total number of words was 123 . On the other hand, the lowest percentage of the lexical density was $41.61 \%$. The text entitled "None of your business!" that was categorized as recount text. It had 62 lexical items, 87 grammatical function words, and the total numbers of words were 149 . Furthermore, we can conclude that the total number of word was not the reason to classify whether a certain text had high percentage of lexical density or difficult to understand and had low percentage of lexical density or easy to understand. The text entitled "Shanti, a Radio Presenter" only had 81 total numbers of words and the text entitled "None of your business!" had 149 total numbers of words. Meanwhile, the result showed that the text entitled "Shanti, a Radio Presenter" had higher percentage of lexical density than the text entitled "None of your business!". It had higher percentage of lexical density because it had more lexical items than grammatical function words. As quoted from Ginting (2012:6) [1], "the higher the lexical density of a text is, the more information there is and the more difficult it is to understand by readers. If the text has more grammatical items than the lexical items, the text as categorized to the lower lexical density. On the contrary, if the text has more lexical items than the grammatical items, the text as categorized to the high lexical density". As we could see, the text entitled "Shanti, a Radio Presenter" had 42 lexical items and 39 grammatical function words. On the 
contrary, the text entitled "None of your business!" had 63 lexical items and 86 grammatical function words. Because of this, the text entitled "Shanti, a Radio Presenter" had higher percentage of lexical density than the text entitled "None of your business!". Thus, it could be informed that the text entitled "Shanti, a Radio Presenter" carried more information and was more difficult to understand by readers than the text entitled "None of your business!".

\section{Conclusion and Suggestion}

Based on the result of the data analysis and discussion in this research, it can be concluded that "English on Sky Textbook" for grade 8 of Junior High School contained three genres of text, namely descriptive, recount and narrative. There are 7 descriptive texts, 12 recount texts, and 5 narrative texts. The dominant genre in this book is recount text.

From 24 reading texts, there are 12 texts that have lower lexical density and 12 texts that have moderate lexical density. However, there is no text that has high lexical density. It means that the texts are not difficult to be understood.

The highest percentage of the lexical density found in the textbook is $57.72 \%$. It is "Camping" which is categorized as descriptive text. It has 71 lexical items, 52 grammatical function words and the total number of words is 123 . On the other hand, the lowest percentage of the lexical density is $41.61 \%$. The text entitled "None of your business!" that is categorized as recount text. It has 62 lexical items, 87 grammatical function words, and the total number of words is 149 .

Based on this result, textbook entitled "English on Sky Textbook" for grade 8 of junior high school published by Erlangga was considered to meet the content of SchoolBased Curriculum. The genres that need to be taught for grade 8 can be found in this textbook. The level of reading texts was easy enough for grade 8 , because the texts were not difficult to learn and understand. After drawing the conclusion, the writer presents some suggestions for the English teacher, the publisher, and the future researchers.

As for the English teacher, The teacher can apply the result of this study as feedback on their teaching activities; improve their knowledge and experience in choosing the suitable and appropriate book. The teacher can give lexical density awareness and background knowledge of lexical items before students read reading text. In understanding meaning of a text, the students need to connect their background knowledge of lexical words to the new knowledge to comprehend the new one.

As for the publisher, they can use this study to provide a textbook with balance composition in providing the genre of text and the level of lexical density. As for the future researcher, The result of the study may give an inspiration to the future researcher to conduct a study on lexical density analysis on different sources or level as well as conducting further analysis by taking interview to the users of the book. The future researcher may analyzing the data with the inter rater to give reliable result.

\section{Daftar Pustaka}

[1] Ginting, Siti Aisah. (2012). Lexical Density of English Reading Texts Vol. 3 No.1. Universitas Negeri Medan.

[2] Nunan, David. (1993). Introducing Discourse Analysis. England: Penguin Group.

[3] Richards, Jack. C. (2012). The Role of Texbooks in a Language Program. New York: Cambridge University Press.

[4] Sholichatun, Siti. (2011). Content Analysis of Reading Materials in English on Sky Textbook for Junior High School. Institut Agama Islam Negeri Walisongo Semarang Fakultas Tarbiyah 